Original Research Paper

\title{
Factors Those Up Regulate Klotho and Glutathione Peroxidase-1 Gene Expression Improve Renal Function in Rats with Acute Renal Failure
}

\author{
${ }^{1}$ Fatma E. El-Gendey, ${ }^{2}$ Shabaan A. Hemeda, ${ }^{3}$ Gamal A. Sosa and ${ }^{4}$ Naglaa F. Alhusseini \\ ${ }^{1}$ Department of Animal Wealth Development, Faculty of Veterinary Medicine, Benha University, Egypt \\ ${ }^{2}$ Department of Animal Wealth Development, Faculty of Veterinary Medicine, Alexandria University, Egypt \\ ${ }^{3}$ Department of Theriogenoology, Faculty of Veterinary Medicine, Benha University, Egypt \\ ${ }^{4}$ Department of Medical Biochemistry and Molecular Biology, Faculty of Medicine, Benha University, Egypt
}

Article history

Received: 17-05-2015

Revised: 06-07-2015

Accepted: 07-07-2015

Corresponding Author:

Naglaa F. Alhusseini

Department of Medical

Biochemistry and Molecular

Biology, Faculty of Medicine,

Benha University Egypt

Email: nagla.alhusseini@fmed.bu.edu.eg

\begin{abstract}
Acute Renal Failure (ARF) has traditionally been defined as the abrupt and progressive loss of kidney functions resulting in the retention of urea and other nitrogenous waste products associated with interstitial inflammation, tubular injury and increasing Tumor Necrosis Factor (TNF). Mortality in patients with ARF remains high $>50 \%$ in severely ill patients. Klotho gene is a new anti-aging gene. Genetic mutation of klotho gene causes multiple premature aging-like phenotypes and shortens lifespan. Klotho gene is highly expressed in the kidney and a soluble form of klotho functions as an endocrine substance that exerts multiple actions including the modulation of renal solute transport and the protection of the kidney. This study aimed to clarify the pre treatment and/or post treatment effect of vitamin $\mathrm{E}$ as an antioxidant on kidney functions, klotho gene expression and glutathione peroxidase- 1 gene expression among rats with acute renal failure. Using glycerol as oxidative stress factor to cause acute renal failure and Real time PCR for assessment of gene expression of target gene in the control and treated groups. Our results demonstrated that the vitamin E ( $\alpha$ tocopherol) as antioxidant factor decreased the kidney injuries as pre renal failure administer and improve kidney function as post renal failure administer. Those effects were through up regulating the Klotho as anti aging gene and the Glutathione Peroxidase (GPx-1) as antioxidant gene expression in the kidney tissue. We concluded that factors those up regulate the klotho gene expression can use as protective factors against kidney injuries and to improve kidney function in renal failure.
\end{abstract}

Keywords: Klotho Gene, Acute Renal Failure, Vitamin E-Glutathione Peroxidase (Gpx-1), Gene Expression

\section{Introduction}

Acute Renal Failure (ARF) has traditionally been defined as the abrupt loss of kidney functions resulting in the retention of urea and other nitrogenous waste products and in the dysregulation of extracellular volume and electrolytes. Mortality in patients with ARF remains high $>50 \%$ in severely ill patients. A correct diagnosis and earliest detection of a particular disorder may save both time and patient. The magnitude of elevation of Serum Creatinine (SCr) and Blood Urea Nitrogen (BUN) are sufficient to diagnose ARF Kaul and Ruhela (2012). Glycerol-induced renal failure causing severe muscle injury (rhabdomyolysis) is accompanied by the release of myoglobin that becomes deposited in the kidney, causing renal failure after $24 \mathrm{~h}$ from injection. Moreover Acute Renal Failure (ARF) causing progressive loss of renal function associated with interstitial inflammation, tubular injury and increasing Tumor Necrosis Factor (TNF) (Kim et al., 2010; Sanz et al., 2010). Antioxidants are widely used in animal models to prevent acute renal failure such as the protective effects of $\mathrm{N}$-acetylcysteine, $\mathrm{N}$-acetylcysteine plus deferoxamine, vitamin $\mathrm{C}$ and vitamin E. (Bernardi et al., 2012; Kongkham et al., 2013; Aldallal, 2013). Vitamin E modulate Glutathione Peroxidase (GPx) activity in kidney, GPX play a critical 
role as antioxidant defense system by catalyzing detoxification of hydrogen peroxide $\left(\mathrm{H}_{2} \mathrm{O}_{2}\right)$ and organic hydroperoxides and the activity of glutathione peroxidase GPx increased in response to vitamin $\mathrm{E}$ treatment Srikanta et al. (2012). Vitamin E (alphatochopherol) was a fat soluble vitamin which regulates oxidation processes in the body, it acts as a powerful antioxidant, vitamin $\mathrm{E}$ could recovered the damaging effect of oxidative stress induced by free radicals causing ARF in rat, it improves oxidative damage and reduces apoptosis in klotho mutant mice (Momeni et al., 2012; Nagai et al., 2003). Klotho gene is a new anti-aging gene. Genetic mutation of klotho gene causes multiple premature aging-like phenotypes and shortens lifespan. Over expression of the klotho gene in mice suppresses aging and extends lifespan which may involve the mechanism of suppression of insulin signaling, suppress oxidant stress and act as a cofactor/co receptor regulating of Fibroblast Growth Factor 23 (FGF 23) signaling (Yuhong and Zhongjie, 2009).

Klotho gene is highly expressed in the kidney and a soluble form of klotho functions as an endocrine substance that exerts multiple actions including the modulation of renal solute transport and the protection of the kidney (Hu et al., 2012). Klotho protein that confers resistance to several pathological conditions predisposing to cardiovascular-renal damage; it is essential in calcium-phosphate metabolism and the maintenance of vascular integrity and offers cardio-renal protection. Reduced levels of soluble klotho protein are detected in the early stages of cardiovascular-renal disease, thus, klotho protein might be considered as a useful biomarker that predicts atherosclerosis, renal disease and vascular calcification (Maltese and Karalliedde, 2012). This study aimed to clarify the effect of glycerol induced ARF on gene expression of both klotho and Glutathione Peroxidase (GPx-1) genes. In addition study the effect of vitamin $\mathrm{E}$ on those expression and kidney function pre and post renal failure.

\section{Subjects and Methods}

\section{Experimental Animals}

Forty-two male albino rats were used in this study. They weighted (180-200 g) at the beginning of the experiment. Rats were obtained from Lab animal care centre, Faculty of Veterinary Medicine (Benha University). Animals were kept for one week before use to acclimatize to the laboratory conditions. The management was kept constant throughout the experimental period. Water and normal balanced ration was offered and re-newed every day. Cages were cleaned regularly twice a week. The rats were divided into 7 groups; each group consisted of six rats. Group I was kept as a control group (negative control). Group II given olive oil orally by gastric tube $\left(5.26 \mathrm{~mL} \mathrm{~kg}^{-1}\right.$ Body Wt.) as olive oil used as solvent of vitamin E. Group III given $50 \%$ glycerol $\left(8 \mathrm{~mL} \mathrm{~kg}^{-1}\right.$, Body wt. intra-muscular divided equally between two hind limbs) Savic et al. (2002). Group IV given 50\% Glycerol as before, then vitamin $\mathrm{E}\left(500 \mathrm{mg} \mathrm{kg}^{-1}\right.$, Body wt.) orally by gastric tube for 18 days (post treatment) everyday. Group $\mathrm{V}$ given Vitamin $\mathrm{E}$ only as before for 18 days. Group VI given Vitamin E for 18 days everyday then 50\% Glycerol (pretreatment). Group VII given Vitamin $\mathrm{E}$ for 18 days everyday then $50 \%$ Glycerol then again Vitamin E for 18 days started after $48 \mathrm{~h}$ everyday (pre and post-treatment).

\section{Blood Samples and Biopsies}

Blood samples were collected from venous plexus before sacrifice for biochemical analysis. The rats sacrificed $48 \mathrm{~h}$ after injection of hypertonic glycerol and for post treatment groups after 20 days from injection of glycerol without any restriction of diet or water Vlahovic et al. (2007). Serum was separated from each blood sample by centrifugation at $3500 \mathrm{rpm}$., stored at $20^{\circ} \mathrm{C}$ for further estimation of urea and creatinine.

Kidneys were removed, immediately placed in Cryo tubes and stored in RNA Later solution (by $10 \mu \mathrm{L}$ per 1 $\mathrm{mg}$ of tissue) (Qiagen-GmbH Hilden, Germany) at- $80^{\circ} \mathrm{C}$ for further assessment of GPx-1 and klotho gene expression.

\section{Assessment Klotho and Glutathione Peroxidase (GPxl) Genes Expressions}

\section{Total RNA Extraction}

Total RNA extraction was done by using total RNA Purification Kit from Jena Bioscience GmbH and according to the manufacturer instructions, about $30 \mathrm{mg}$ tissue put in a micro centrifuge tube with $300 \mu \mathrm{L}$ of lysis buffer containing 2ME (2 Mercapto Ethanol) was homogenized using rotor Tissue Rupror (Qiagen, $\mathrm{GmbH}$ ) (Yousef et al., 2014).

\section{Spectrophotometric Quantification of RNA}

The absorbance of Nanodrop spectrophotometer (USA) was measured $\mathrm{A}_{260}$ and $\mathrm{A}_{280}$. Concentration of RNA sample was measured 44 ug $\mathrm{mL}^{-1} \mathrm{~A}_{260}$ (Wilfinger et al., 1997). The ratio of the reading at $\left(\mathrm{A}_{260} / \mathrm{A}_{280}\right)$ provides am estimate of the purity of RNA. Pure RNA has an $\mathrm{A}_{260} / \mathrm{A}_{280}$ ratio of 1.9 to 1.3.

\section{Two Steps RT-PCR}

1st step: Template RNA $(5 \mu \mathrm{L})$ and distilled water $(15 \mu \mathrm{L})$ were added to Maxine RT pre mix tube. cDNA synthesis (Reverse transcription) reaction using G-storm Thermalcycler (Ingland) was performed at a temperature of $45^{\circ} \mathrm{C}$ for $60 \mathrm{~min}$ followed by RTase inactivation step at $95^{\circ} \mathrm{C}$ for $5 \mathrm{~min}$. This reactant was diluted by adding 
$30 \mathrm{~mL}$ nuclease free water (Yousef et al., 2014). 2nd step: RT-PCR was done using ABI 7900HT fast real time PCR (applied Biosystem USA), the prepared reaction components were done in 96 well PCR plate (micro Amp (R 90 well optical reaction plate with Barcode, code 128). The reaction was done using qPCR Green Master from (Jena Bioscience $\mathrm{GmbH}$ ), using real time cycler conditions of $95^{\circ} \mathrm{C}$ and $5 \mathrm{~min}$ (Initial denaturation), followed by 35 cycles of $95^{\circ} \mathrm{C}, 30 \mathrm{~s}, 55^{\circ} \mathrm{C}, 1 \mathrm{~min}$ and $72^{\circ} \mathrm{C}, 30 \mathrm{~s}$ for denaturation, annealing and extension steps, respectively. The primer sequences were from (5'-3') for all genes, Klotho gene forward 5' -CGT GAA TGA GGC TCT GAA AGC- 3' reverse 5'- GAG CGG TCA CTA AGC GAA TAC G- 3', GPx1 forward 5' -ATG TCT GCT GCT CGG CTC TC -3' reverse 5' -GTT GCT AGG CTG CTT GGA CAG $-3^{\prime}$ and $\beta$-actin as endogenous control forward 5'- CCC ATT GAA CAC GGC ATT G -3' reverse- GTA CGA CCA GAG GCA TAC A -3'.

\section{Data Analysis}

According to the RQ manager program 1.2 ABI SDS software (ABI 7900 HT), the data are produced as sigmoid shaped amplification plots in which the number of cycle is plotted against fluorescence (when using linear scale). Because the samples of control group are used as calibrators, the expression levels are set to 1 . But because the gene expression levels were plotted as $\log 10$ values $(\log 10$ of 1 is 0$)$, the expression level of the calibrator samples appear as 0 in the graph. Because the relative quantities of the Klotho or GPxl genes are normalized against the relative quantities of the endogenous control $\beta$-actin gene fold expression changes are calculated using the equation $2^{-\Delta \Delta \mathrm{CT} \text {. }}$

\section{Statistical Analyses}

The collected data was tabulated and statistically analyzed. The results are presented as means \pm Standard Error (SE) (ANOVA test).

All analysis was performed using the Statistics Package for Social Sciences (SPSS) and Microsoft office Excel is used for data processing and data analysis. Differences are considered as statistically significant for $\mathrm{p}$ values less than 0.05 .

\section{Results}

\section{Genes Expression by Real Time PCR}

The obtained data from real time PCR found in Fig. 1 illustrated that the expression level of GPx-1 and Klotho mRNA. The comparison of gene expression among different groups was divided into two stages. Stage I: Negative control samples used as a calibrator, the expression levels are set to one. The expression levels were blotted as $\log 10$ values (and $\log 10$ of 1 is 0 ), the expression levels of the negative control samples appear as 0 in graph. Also the relative quantities of targeted mRNA are normalized against the relative quantities of $\beta$-actin (endogenous control). The expression level of endogenous control is 0 , so there are no bars for $\beta$-actin and found that the expression levels was decreased to became ( 0.899 fold and 0.91 folds) in kidney samples of glycerol treated group (Fig. 1). Stage II: Used ARF group as a calibrator. The expression levels are set to one, so the expression levels of the glycerol treated (ARF) group (A) appear as 0 in graph (Fig. 2). The results revealed the following.

\section{Expression of GPx-1}

The expression level of GPx-1 gene in kidney samples was significant highly increased in vitamin $\mathrm{E}$ administration pre plus post ARF by 5.78 folds. Also it significantly increased in vitamin $E$ post $A R F$ and vitamin $\mathrm{E}$ pre-ARF groups by 2.84 and 1.26 fold respectively $\mathrm{p}<0.05$.

\section{Expression of Klotho Gene}

The expression of klotho mRNA was significantly increased in vitamin $\mathrm{E}$ administration post-ARF, pre plus post ARF and pre-ARF groups (4.71, 4.72 and 1.74 folds respectively) $\mathrm{p}<0.05$.

Table 1 showed that the means of Log 10 relative units of GPX-1 mRNA expressions levels in control and glycerol treated groups $(5.17 \pm 0.08184$ and $5.11 \pm 0.08184)$. GPx-1 mRNA expressions in kidney samples were significantly increased in vit $\mathrm{E}$ pre plus post treatment $(5.88 \pm 0.08184)$. Also there were a significant difference between vit $\mathrm{E}$ post-treatment, vit $\mathrm{E}$ and pre-treatment with vit E $(5.45 \pm 0.08184$, $5.44 \pm 0.08184$ and $5.22 \pm 0.08184$ respectively).

\section{Kidney Functions (Creatinine and Blood Urea Nitrogen)}

Creatinine levels in control and and olive oil control and vitamin $\mathrm{E}$ group were $0.67 \pm 0.06,0.83 \pm 0.13$ and $0.73 \pm 0.12$ respectively and the level of creatinine was significantly increased in glycerol induced renal failure group $(4.97 \pm 0.75)) \mathrm{p}<0.001$. The groups treated by vit E significantly returned creatinine to control normal levels. Pre-treatment, post-treatment and pre-plus post treatment levels were $0.71 \pm 0.05,0.74 \pm 0.074$ and $0.72 \pm 0.001$ respectively $\mathrm{p}<0.001$.

The findings showed that the levels of Blood Urea Nitrogen (BUN) in control, control olive oil group and vitamin E were $24.43 \pm 2.18,31.83 \pm 2.89$ and $34.22 \pm 2.24$ respectively and BUN was significantly increased in glycerol induced renal failure $(242.03 \pm 41.93) \mathrm{p}<0.001$. Groups treated by vit E with glycerol causing a significant reduction in BUN levels in pre-treatment, post-treatment and pre-plus post treatment at levels 52.64 \pm 3.08 , $40.03 \pm 1.76$ and $46.37 \pm 2.79$ respectively) $\mathrm{p}<0.05$. 


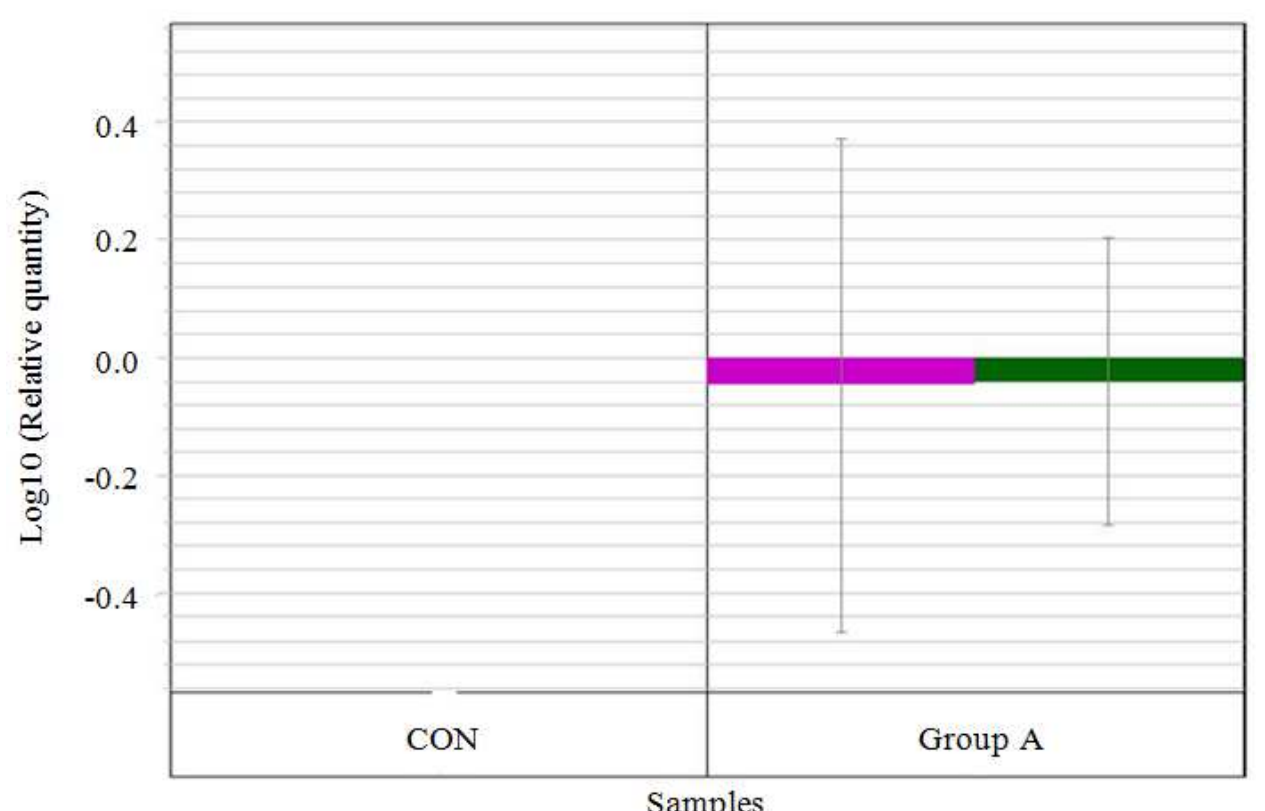

Fig. 1. Gene expression levels of Klotho and Gpx-1 m-RNA in kidney for control samples as a calibrator group and glycerol group (A), CON (a) = Control. Group A = Glycerol (ARF) group (50\% glycerol, 8 mL kg ${ }^{-1}$, B.wt) $\square$ GPX-1 gene expression. Klotho gene expression

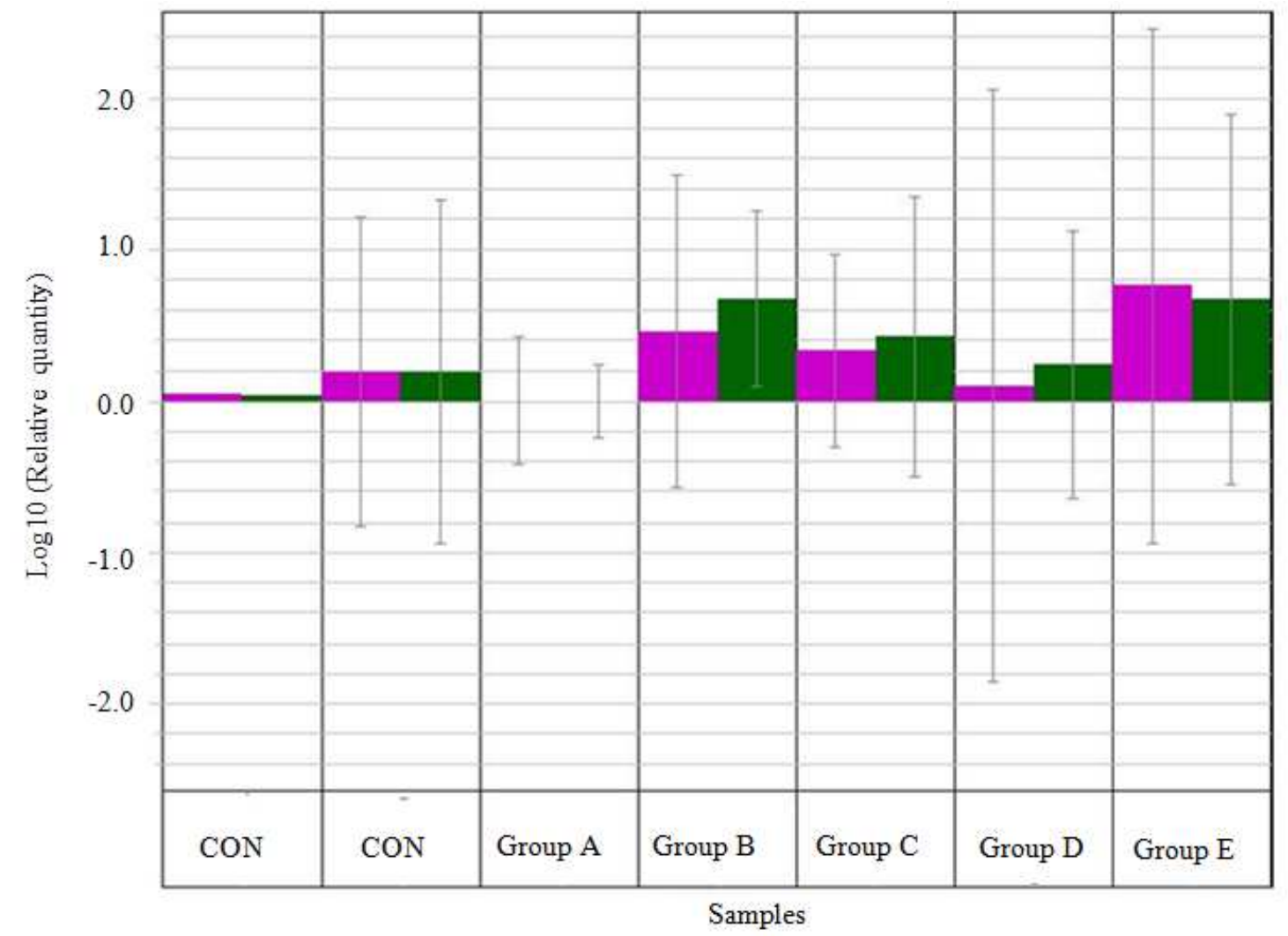

Fig. 2.Gene expression levels of Klotho and GPx-1 m-RNA in kidney samples of control and treated groups compared with kidney samples of Glycerol (ARF) group (A) as a calibrator group, $a=$ control, $b=$ olive oil control, $A=$ Glycerol $(A R F), B=G l y e r o l+$ vit $\mathrm{E}, \mathrm{C}=$ vit $\mathrm{E}, \mathrm{D}=$ vit $\mathrm{E}+$ glycerol, $\mathrm{E}=$ vit $\mathrm{E}+$ glycerol + vit $\mathrm{E}, \boldsymbol{G P X}-1$ gene expression. $\square$ Klotho gene expression 


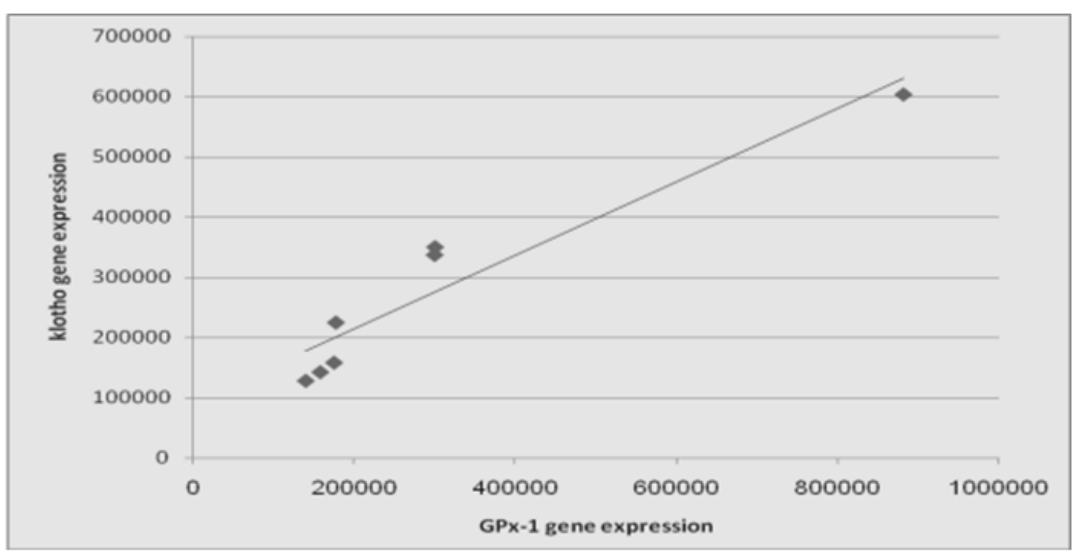

Fig. 3. Correlation between klotho and glutathione peroxidase-1 gene expression (significant positive correlation)

Table 1. Mean \pm Standard error of Log 10 relative units of both GPx-1 and klotho mRNA expressions in kidney of control and treated groups

\begin{tabular}{lll}
\hline Groups & GPx-1 Gene expression & Klotho Gene expression \\
\hline Control & $5.17 \pm 0.08184^{\mathrm{c}}$ & $5.12 \pm 0.08184^{\mathrm{c}}$ \\
Olive oil control & $5.21 \pm 0.08184^{\mathrm{b}, \mathrm{c}}$ & $5.17 \pm 0.08184^{\mathrm{c}}$ \\
$50 \%$ glycerol (ARF) & $5.11 \pm 0.08184^{\mathrm{c}}$ & $5.08 \pm 0.08195^{\mathrm{c}}$ \\
Vitamin E post-ARF & $5.45 \pm 0.08184^{\mathrm{b}}$ & $5.51 \pm 0.08195^{\mathrm{b}}$ \\
Vitamin E pre and post ARF & $5.44 \pm 0.08184^{\mathrm{b}}$ & $5.49 \pm 0.08195^{\mathrm{b}}$ \\
Vitamin E pre-ARF & $5.22 \pm 0.08184^{\mathrm{b}, \mathrm{c}}$ & $5.32 \pm 0.08195^{\mathrm{b}, \mathrm{c}}$ \\
Vitamin E (pre + post-ARF) & $5.88 \pm 0.08184^{\mathrm{a}}$ & $5.75 \pm 0.08195^{\mathrm{a}}$ \\
\hline
\end{tabular}

Means having different letters are significantly different at the level of $\mathrm{p}<0.05$

The relation between GPx-1 gene expression and both creatinine and BUN showed non significant negative correlation $(\mathrm{r}=-0.25$ and -0.20$)$. Also non significant negative correlation between klotho gene expression and both creatinine $(\mathrm{r}=-0.32)$ and BUN $(\mathrm{r}=$ 0.26) $\mathrm{p}[0.05$. A significant positive correlation was found between klotho gene expression and GPX-1 gene expression $(\mathrm{r}=0.96)(\mathrm{p}<0.001)$ Fig. 3 .

\section{Discussion}

This study demonstrates the severity of renal injury during acute renal failure caused by deep intra muscular injection of glycerol. It may be due to increased amounts of free radicals. Treatment with vitamin $\mathrm{E}$ as pretreatment, post-treatment and pre plus post-treatment may reduce renal injury during glycerol induced ARF. Up-regulated the Glutathione Peroxidase (GPx-1) and klotho gene expression in the kidney and provide the most effective renal protection.

Klotho gene was expressed in multiple tissues and organs, but by far its highest expression is in the kidney. The klotho mutant mouse suffered from multiple disorders, resembling human premature-aging syndromes Cardon and Bell (2001).

The observed results revealed down regulation of $G P x-1$ gene expression in glycerol induced renal failure group. These results of the effect of glycerol on GPx-1 gene expression agree with Baliga et al. (1997) who found that, the oxidative stress increasing in ARF is one of the key underlying mechanisms in nephropathy pathogenesis. Impairment in the antioxidant defense mechanism, including increased lipid peroxidation and inactivation of antioxidant enzymes including catalase, superoxide dismutase and GPx.

Moreover GPx activity had been reported to be reduced in plasma of patients with end-stage renal disease Koenig et al. (1997). Also Ghatak et al. (1999) found that a significant reduction in plasma scavenging enzyme activities as GPx in patients with oxidative stress. Similarly in the Adriamycin model of renal failure, renal cortex GPx activity was decreased to $69 \%$ of the control levels at 20 weeks after Adriamycin treatment Van den Branden et al. (2000). These results also are in a harmony with the recorded data by Macdonald et al. (2003) explained the oxidative stress occurs when a balance is disrupted by excessive production of Reactive Oxygen Speacies (ROS), including superoxide, hydrogen peroxide and hydroxyl radicals and/or by inadequate antioxidant defenses, including suboptimal levels of catalase, Glutathione Peroxidase (GPx), vitamins $\mathrm{C}$ and $\mathrm{E}$ and reduced glutathion. Sener et al. (2004) found that in the erythrocytes of male Wistar albino rats at 4 weeks after 5/6 nephrectomy, GPx activity was found to be reduced, in addition Devinder et al. (2004) found that the glycerol treated group showed depletion in antioxidant system which indicated by the significant decrease in the levels 
of glutathione reductase and superoxide dismutase enzymes. Pandir and Kara (2013) clarified that Superoxide Dismutase (SOD), catalase (CAT) and Glutathione Peroxidase (GPx) activities were decreased and malondialdehyde MDA levels were increased in the cisplatin nephrotoxicity group. The obtained results were not in accordance with Noori and Mahboob (2010) who found that oxidative stress is another participating factor associated with cisplatin-induced renal damage. SOD, CAT and GPx activities are increased in cellular membranes due to cisplatininduced nephrotoxicity. Also Yousef et al. (2014) found that the glycerol induced renal failure in rats causing minimal increased in the GPx-1 gene expression but after $24 \mathrm{~h}$ from glycerol treatment.

The expression level of kotho mRNA decreased in kidney samples of glycerol treated group from control group. This findings agree with Ohyama et al. (1998) suggesting that the expression of klotho is modulated by acute inflammatory stress in vivo. Similarly Saito et al. (2003) and Mitobe et al. (2005) were proved that the oxidative stress can decrease klotho mRNA and protein in a cultured cell line and increased Tumor Necrosis Factor (TNF) and interferon- $\gamma$ (IFN- $\gamma$ ) in acute kidney injury lead to klotho down-regulation. In addition Sugiura et al. (2005) reported that the renal klotho mRNA and protein expressions were significantly reduced in the rats with renal failure assessed by real-time PCR or western blotting. These results came in accordance with the recorded data of $\mathrm{Hu}$ et al. (2010) and Thurston et al. (2010) were found that klotho down-regulation occurs before changes in other markers of kidney damage. It takes place only $3 \mathrm{~h}$ post-ARF may be due to activation and induction of nitric oxide production.

The results illustrated that, vitamin $\mathrm{E}$ showed protective effect and decrease occurrence of renal failure through improving GPX-1 gene expression.

The obtained result data in Table 1 were agree with (Wagner et al., 1996; Bowry et al., 1992) they reported that vitamin $\mathrm{E}$ acts as a pro-oxidant by activation of enzymatic antioxidant (SOD and GPx), leading to increase lipid peroxidation and also its capacity of free radical scavenger is a dose dependent manner. Also Kheir-Eldin et al. (2001) found that Administration of $\mathrm{N}$-acetylcysteine along with atocopherol (vitamin E) suppressed necrosis factor kappa (B) NF $\kappa$ B activation and with vitamin $E$ and $\beta$ carotene it reduced lipid peroxidation and restored glutathion levels in endotoxic rats. The antioxidant action of $\alpha$-Tochopherol (vit E) may be due to its ability to scavenge free radicals and to enhance the cellular antioxidant like reduced glutathione, GPx and super oxide dismutase and thereby it prevents lipid peroxidation (Morimoto et al., 2005).

Hajiani et al. (2008) reported that the antioxidant property of vitamin $\mathrm{E}$ is not only to scavenge reactive oxygen species ROS, but also to up-regulate antioxidant enzymes through regulation of the gene expression or activity of antioxidant enzymes. Also Srikanta et al. (2012) found that GPx-1 activity increased in response to vitamin $\mathrm{E}$ treatment.

The expression of klotho gene was increased with vitamine $\mathrm{E}$ administration both pre $\mathrm{ARF}$ and post ARF. The results agree with Nagai et al. (2003) who found that the klotho mutant mice exhibit increased apoptosis and increased oxidative damages to lipid and DNA. Furthermore, treatment of klotho mutant mice with an antioxidant $\alpha$ tocopherol attenuates oxidative damage and reduces apoptosis and also causing upregulation in klotho gene expression.

The results illustrated that vitamin E showed protective effect and decrease occurrence of renal failure through recovered renal function to its normal levels. The data revealed that treatment by vitamin $\mathrm{E}$ at a dose $500 \mathrm{mg} \mathrm{kg}{ }^{-1}$ B.wt/daily for 18 days orally returned creatinine to control normal levels. Weber et al. (2003) found that the vit E acts to reduce free-radical and lipid peroxidation formation on cell membranes, consequences initiated by oxidant-antioxidant imbalance and to decrease cell damage. The high dosages of vitamin $E$ found to be effectively protective of the renal functions from oxidative changes in rat models Naziroglu et al. (2004). Moreover the previous findings also agree with Derakhshanfar et al. (2007) provides evidence that pre-treatment of vitamin $\mathrm{E}$ can prevent both the functional and histological renal changes in nephtotoxicity. Similar results found by Koh et al. (2001) and Imura et al. (2004) reported severely reduced production of klotho in urine and kidneys (messenger RNA and protein) by Western blot of patients with acute renal failure and klotho levels have been shown to correlate negatively with plasma creatinine levels. Also the previous results come in harmony with the results obtained by El-Far et al. (2005) found the presence of significant negative correlation between GPx activity and serum creatinine level. Also, a highly significant negative correlation was found between GPx and blood urea nitrogen. Moreover Shih and Yen (2007) were evaluated the correlation between anti-aging gene (klotho) and antioxidant status and many important antioxidant enzymes such as glutathione peroxidase.

It is important to spot on the role of Klotho gene expression on improve the renal function as $\mathrm{Hu}$ et al. (2012) demonstrated that up-regulation of endogenous Klotho protect the kidney from renal insults, preserve kidney function and suppress renal fibrosis, in chronic kidney disease. Klotho is a highly promising candidate on the horizon as an early biomarker and as a novel therapeutic agent for chronic kidney disease. In addition Manya et al. (2010) reported that aged mice (29 months) have low renal Klotho protein expression 
compared to young mice (4 weeks). Furthermore, aged rats (male, 27 months) have significantly higher serum creatinine than that of young rats (12-months). Notably, aged rats have significantly decreased renal Klotho protein levels along with increase in oxidative stress, overproduction of proinfiammatory cytokine and activation of endothelin signal transduction.

Cell senescence and oxidative stress are closely associated and implicated in acute and chronic kidney disease. Mice with spontaneous chronic glomerular disease carrying a mutation in Tensin2 have low renal Klotho, high level of lipid peroxidation, superoxide anion production, mitochondrial oxidative stress and severe cell senescence in the kidney. Genetic Klotho over expression ameliorates renal injury associated with a dramatic improvement in mitochondria damage, reduction in senescent cells, decreased oxidant stress and reduced apoptosis in the kidney (Haruna et al., 2007).

$\mathrm{Hu}$ et al. (2012) study illustrated that the potential utility of Klotho in clinical practice is at least two-fold. First, Klotho could serve as an early and sensitive biomarker of presence of kidney diseases. Second, Klotho supplementation may provide novel therapy for Acute Kidney Injuries (AKI) patients to retard or block its progression to $\mathrm{CKD}$ and for $\mathrm{CKD}$ by slowing progression as well as preventing and reversing complications. The immediate challenge is to how to more efficiently increase Klotho levels in patients with kidney disease by stimulating endogenous Klotho or giving recombinant Klotho.

View of all study results demonstrated that the vitamin $\mathrm{E}$ ( $\alpha$ tocopherol) as antioxidant factor decreased the kidney injuries as pre renal failure administer and improve kidney function as post renal failure administer. Those effects were through up regulating the Klotho as anti aging gene and the Glutathione Peroxidase (GPx-1) as antioxidant gene expression in the kidney tissue.

\section{Conclusion}

We concluded that factors those up regulate the klotho gene expression can use as protective factors against kidney injuries and to improve kidney function in renal failure.

\section{Acknowledgement}

Special thanks to Prof. Amal Idris; Head of Molecular Bilogy Unit MBU, Faculty of Medicine, Benha University, for fruitiful cooperation and big help.

\section{Funding Information}

This study was done by self-financing.

\section{Author's Contributions}

Fatma E. El-Gendey: Collecting samples and clinical data, collecting the scientific materials and application of the experiment.

Shabaan A. Hemeda: Conception and design, analysis and interpretation of data, drafting the article.

Gamal A. Sosa: Supervision on the research steps.

Naglaa F. Alhusseini: Molecular biology technique, analysis and interpretation of data, contributed unpublished essential data, writing the manuscript and corresponding author.

\section{Ethics}

We confirm that this manuscript has not been published elsewhere and is not under consideration by another journal. Each author confirms the manuscript represents honest work. All authors have approved the manuscript. Each author agrees with the order in which his name appears on the title page. Study design and methods were approved by Ethics Committee of Benha Faculty of Medicine.

\section{References}

Aldallal, A.A.R., 2013. Vitamin C, an antioxidant attenuates gentamicin-induced acute kidney injury in female albino Wister rats. Med. J. Babylon, 10: 656-661.

Baliga, R., N. Ueda, P.D. Walker and S.V. Shah, 1997. Oxidant mechanisms in toxic acute renal failure. Am. J. Kidney Dis., 29: 46577. DOI: 10.1016/S0272-6386(97)90212-2

Bernardi, R.M., L. Constantino, R.A. Machado, F. Vuolo and P. Budni et al., 2012. N-acetylcysteine and deferrioxamine protects against acute renal failure induced by ischemia/reperfusion in rats. Rev. Bras. Ter. Intensiva, 24: 219-223. DOI: $10.1590 / \mathrm{S} 0103-507 X 2012000300003$

Bowry, V.W., K.U. Ingold and R. Stocker, 1992. Vitamin E in human low-density lipoprotein. When and how this antioxidant becomes a pro-oxidant. Biochem. J., 288: 341-344. PMID: 1463440

Cardon, L.R. and J.I. Bell, 2001. Association study designs for complex diseases. Nat. Rev. Genet, 2: 91-99. DOI: $10.1038 / 35052543$

Derakhshanfar, A., A. Bidadkosh and S. Kazeminia, 2007. Vitamin E protection against gentamicininduced nephrotoxicity in rats: A biochemical and histopathologic study. J. Vet. Res., 8: 230-238.

Devinder, S., C. Vikas and C. Kanwaljit, 2004. Protective effect of naringin, a bioflavonoid on glycerol-induced acute renal failure in rat kidney. Toxicology, 201: 143-151.

DOI: 10.1016/J.TOX.2004.04.018 
El-Far, M.A., M.A. Bakr, S.E. Farahat and E.A. Abd El-Fattah, 2005. Glutathione peroxidase activity in patients with renal disorders. Clin. Exp. Nephrol., 9: 127-131. DOI: $10.1007 / \mathrm{s} 10157-005-0343-1$

Ghatak, A., M.J.S. Brar, A. Agarwal, N. Goel and A.K. Rastogi et al., 1999. Oxy free radical system in heart failure and therapeutic role of oral vitamin E. Int. J. Cardiol., 57: 119-127. DOI: $10.1016 / \mathrm{S} 0167-5273(96) 02787-8$

Hajiani, M., A. Golestani, A. Shariftabrizi, R. Rastegar and S. Payabvash et al., 2008. Dose-dependent modulation of systemic lipid peroxidation and activity of anti-oxidant enzymes by vitamin $\mathrm{E}$ in the rat. Redox Rep., 13: 60-66.

DOI: $10.1179 / 135100008 X 259114$

Haruna, Y., N. Kashihara, M. Satoh, N. Tomita and T. Namikoshi et al., 2007. Amelioration of progressive renal injury by genetic manipulation of Klotho gene. Proc. Nat. Acad. Sci. USA, 104: 2331-2336.

DOI: $10.1073 /$ pnas.0611079104

$\mathrm{Hu}$, M.C., O.M. Kuro and O.W. Moe, 2012. The emerging role of Klotho in clinical nephrology. Adv. Exp. Med. Biol., 27: 2650-2657. DOI: $10.1093 / \mathrm{ndt} / \mathrm{gfs} 160$

Hu, M., M. Shi, J. Zhang, H. Quiñones and M. Kuro-o et al., 2010. Klotho deficiency is an early biomarker of renal ischemia-reperfusion injury and its replacement is protective. Kidney Int., 78: 1240-1251. DOI: 10.1038/ki.2010.328

Imura, A., A. Iwano, O. Tohyama, Y. Tsuji and K. Nozaki et al., 2004. Secreted Klotho protein in sera and CSF: Implication for post-translational cleavage in release of Klotho protein from cell membrane. FEBS Lett., 565: 143-147.

DOI: 10.1016/j.febslet.2004.03.090

Kaul, A. and V. Ruhela, 2012. Approach to a patient with acute kidney injury. Clin. Queries Nephrol., 1: 6-12. DOI: 10.1016/S2211-9477(11)70017-6

Kheir-Eldin, A.A., T.K. Motawi, M.Z. Gad and H.M. Abd-ElGawad, 2001. Protective effect of vitamin E, $\beta$-carotene and $N$-acetylcysteine from the brain oxidative stress induced in rats by lipopolysaccharide. Int. J. Biochem. Cell Biol., 33: 475-482. DOI: 10.1016/S1357-2725(01)00032-2

Kim, J.H., S.S. Lee, M.H. Jung, H.D. Yeo and H. Kim et al., 2010. N-acetylcysteine attenuates glycerolinduced acute kidney injury by regulating MAPKs and Bcl-2 family proteins. Nephrol. Dial. Transplant, 25: 1435-1443. DOI: $10.1093 / \mathrm{ndt} / \mathrm{gfp} 659$

Koenig, J.S., M. Fischer, E. Bulant, B. Tiran and I. Elmadfa et al., 1997. Antioxidant status in patients on chronic hemodialysis therapy: Impact of parenteral selenium supplementation. Wien. Klin. Wochenschr., 109: 13-19. PMID: 9037743
Koh, N., T. Fujimori and S. Nishiguchi, 2001. Severely reduced production of klotho in human chronic renal failure kidney. Biochem. Biophys. Res. Commun., 280: 1015-1020. DOI: 10.1006/bbrc.2000.4226

Kongkham, S., S. Sriwong and A. Tasanarong, 2013. Protective effect of alpha tocopherol on contrastinduced nephropathy in rats. Revista Nefrología, 33: 116-139. DOI: 10.3265/Nefrologia.pre2012.Nov.11736

Macdonald, J., H. Galley and N. Webster, 2003. Oxidative stress and gene expression in sepsis. Br. J. Anaesth., 90: 221-232. DOI: 10.1093/bja/aeg034

Maltese, G. and J. Karalliedde, 2012. The putative role of the antiageing protein klotho in cardiovascular and renal disease. Int. J. Hypertens, 2012: 1-5. DOI: $10.1155 / 2012 / 757469$

Manya, H., K. Akasaka-Manya and T. Endo, 2010. Klotho protein deficiency and aging. Geriatrics Gerontol. Int., 10: S80-S87. DOI: $10.1111 /$ j.1447-0594.2010.00596.x

Mitobe, M., T. Yoshida, H. Sugiura, S. Shirota and K. Tsuchiya et al., 2005. Oxidative stress decreases klotho expression in a mouse kidney cell line. Nephron Exp. Nephrol., 101: 67-74.

DOI: $10.1159 / 000086500$

Momeni, H.R., S. Oryan and N. Eskandari, 2012. Effect of vitamin $\mathrm{E}$ on sperm number and testis histopathology of sodium arsenite-treated rats. Reproductive Biol., 12: 171-181. DOI: $10.1016 / \mathrm{S} 1642-431 \mathrm{X}(12) 60084-9$

Morimoto, H., K. Nakao, K. Fukuoka, A. Sarai and A. Yano et al., 2005. Long-term use of vitamin Ecoated polysulfone membrane reduces oxidative stress markers in haemodialysis patients. Nephrol. Dial. Transplant, 20: 2775-2782. DOI: $10.1093 / \mathrm{ndt} / \mathrm{gfi} 121$

Nagai, T., K. Yamada and H.C. Kim, Y.S. Kim and Y. Noda et al., 2003. Cognition impairment in the genetic model of aging klotho gene mutant mice: A role of oxidative stress. FASEB J., 17: 50-52. DOI: $10.1096 /$ fj.02-0448fje

Naziroglu, M., A. Karaoglu and A.O. Aksoy, 2004. Selenium and high dose vitamin E administration protects cisplatin-induced oxidative damage to renal, liver and lens tissues in rats. Toxicology, 195: 221-230. DOI: 10.1016/J.TOX.2003.10.012

Noori, S. and T. Mahboob, 2010. Antioxidant effect of carnosine pretreatment on cisplatin-induced renal oxidative stress in rats. Ind. J. Clin. Biochem., 25: 86-91. DOI: $10.1007 / \mathrm{s} 12291-010-0018-\mathrm{x}$

Ohyama, Y., M. Kurabayashi, H. Masuda, T. Nakamura and Y. Aihara et al., 1998. Molecular cloning of ratklothocdna: Markedly decreased expression of klotho by acute inflammatory stress. Biochem. Biophys. Res. Commun., 251: 920-925.

DOI: $10.1006 /$ bbrc. 1998.9576 
Pandir, D. and O. Kara, 2013. Cisplatin-induced kidney damage and the protective effect of bilberry (Vaccinium myrtillus L.): An experimental study Turk. J. Med. Sci., 43: 951-956.

DOI: $10.3906 /$ sag-1210-82

Saito, K., N. Ishizaka, H. Mitani, M. Ohno and R. Nagai, 2003. Iron chelation and a free radical scavenger suppress angiotensin II-induced downregulation of klotho, an anti-aging gene, in rat. FEBS Lett., 551: 58-62. DOI: 10.1016/S0014-5793(03)00894-9

Sanz, A.B., M.D. Sanchez-Nino, A.M. Ramos, J.A. Moreno and B. Santamaria et al., 2010. NF- $\kappa$ B in renal inflammation. J. Am. Society Nephrol., 21: 1254-1262. DOI: 10.1681/ASN.2010020218

Savic, V., P. Vlahovic, V. Djordjevic, M. MiticZlatkovic and V. Avramovic et al., 2002. Nephroprotective effects of pentoxifylline in experimental myoglobinuric acute renal failure. Pathol. Biol., 50: 599-607. DOI: $10.1016 / \mathrm{S} 0369-8114(02) 00323-1$

Sener, G., K. Paskaloglu, H. Toklu, C. Kapucu and G. Ayanoglu-Dulger et al., 2004. Melatonin ameliorates chronic renal failure-induced oxidative organ damage in rats. J. Pineal Res., 36: 232-241. DOI: $10.1111 /$ j.1600-079X.2004.00113.X

Shih, P. and G. Yen, 2007. Differential expressions of antioxidant status in aging rats: The role of transcriptional factor $\mathrm{Nrf} 2$ and MAPK signaling pathway. Biogerontology, 8: 71-80. DOI: $10.1007 / \mathrm{s} 10522-006-9033-y$

Srikanta, J., C. Gagan and D. Jagneshwar, 2012. Expression of antioxidant genes in renal cortex of PTU-induced hypothyroid rats: Effect of vitamin E and curcumin. Acad. J. Molecul. Biol. Rep., 9: 1193-1203. DOI: $10.1007 / \mathrm{s} 11033-011-0849-4$

Sugiura, H., T. Yoshida, K. Tsuchiya, M. Mitobe and S. Nishimura et al., 2005. Klotho reduces apoptosis in experimental ischaemic acute renal failure. Nephrol. Dial. Transplant, 20: 2636-2645.

DOI: $10.1093 /$ ndt/gfi 165
Thurston, R.D., C.B. Larmonier P.M. Majewski, R. Ramalingam and M. Midura-Kiela et al., 2010. Tumor necrosis factor and interferon- $\gamma$ downregulate klotho in mice with colitis. Gastroenterology, 138: 1384-1394. DOI: $10.1053 /$ j.gastro.2009.12.002

Van den Branden, C., B. Ceyssens, D. De Craemer, P. De Bleser and K. Hellemans et al., 2000. Antioxidant enzyme gene expression in rats with remnant kidney induced chronic renal failure. Exp. Nephrol., 8: 91-96. DOI: 10.1159/000020654

Vlahovic, P., T. Cvetkovic, V. Savic and V. Stefanovic, 2007. Dietary curcumin does not protect kidney in glycerol-induced acute renal failure. Food Chem. Toxicol., 45: 1777-1782. DOI: $10.1016 /$ j.fct.2007.04.004

Wagner, B.A., G.R. Buettner and C.P. Burns, 1996. Vitamin $\mathrm{E}$ slows the rate of free radical-mediated lipid peroxidation in cells. Arch. Biochem. Biophys., 334: 261-268. DOI: 10.1006/ABBI.1996.0454

Weber, S.U., J.J. Thiele, N. Han, C. Luu and G. Valacchi et al., 2003. Topical $\alpha$-tocotrienol supplementation inhibits lipid peroxidation but fails to mitigate increased transepidermal water loss after benzoyl peroxide treatment of human skin. Free Radical Biol. Med., 34: 170-176. DOI: $10.1016 / \mathrm{S} 0891-5849(02) 01187-5$

Wilfinger, W.W., K. Mackey and P. Chomczynski, 1997. Effects of PH and ionic strength on the spectrophotometric assessment of nucleic acid purity. Biotechniques, 22: 474-481. PMID: 9067025

Yousef, M.M., N.F. Alhusseini, H.A. Mohamed, R. Eldesoky and M.M. Zaki, 2014. Role of ginger extract and $\mathrm{N}$-acetylcysteine in acute renal tubular necrosis: Histological, immunohistochemical and gene expression study in rats. Cell boil. Genet. J., 4: 27-39. DOI: $10.5897 /$ JCBG2014.0038

Yuhong, W. and S. Zhongjie, 2009. Current understanding of klotho. Ageing Res. Rev., 8: 43-51. DOI: 10.1016/j.arr.2008.10.002 